\title{
Boron: A key element in radical reactions*
}

\author{
Philippe Renaud ${ }^{\ddagger}$, Alice Beauseigneur, Andrea Brecht-Forster, \\ Barbara Becattini, Vincent Darmency, Sarkunam Kandhasamy, \\ Florian Montermini, Cyril Ollivier, Philippe Panchaud, Davide Pozzi, \\ Eoin Martin Scanlan, Arnaud-Pierre Schaffner, and Valéry Weber
}

\author{
Department of Chemistry and Biochemistry, University of Berne, Freiestrasse 3, \\ CH-3000 Berne 9, Switzerland
}

\begin{abstract}
Boron derivatives are becoming key reagents in radical chemistry. Here, we describe reactions where an organoboron derivative is used as a radical initiator, a chain-transfer reagent, and a radical precursor. For instance, $B$-alkylcatecholboranes, easily prepared by hydroboration of alkenes, represent a very efficient source of primary, secondary, and tertiary alkyl radicals. Their very high sensitivity toward oxygen- and heteroatom-centered radicals makes them particularly attractive for the development of radical chain processes such as conjugate addition, allylation, alkenylation, and alkynylation. Boron derivatives have also been used to develop an attractive new procedure for the reduction of radicals with alcohols and water. The selected examples presented here demonstrate that boron-containing reagents can efficiently replace tin derivatives in a wide range of radical reactions.
\end{abstract}

Keywords: radicals; catecholboranes; organoboranes; allylation; alkenylation; alkynylation; cyanation; reduction; hydrogen atom donor.

\section{INTRODUCTION}

The ability of organoboron compounds to participate in free radical reactions has been identified since the earliest investigation of their chemistry [1-3]. For instance, the autoxidation of organoboranes (Scheme 1) has been proven to involve radical intermediates [4,5]. This reaction has led recently to the use of triethylborane as a universal radical initiator functioning under a very wide range of reaction conditions (temperature and solvent) [6,7].

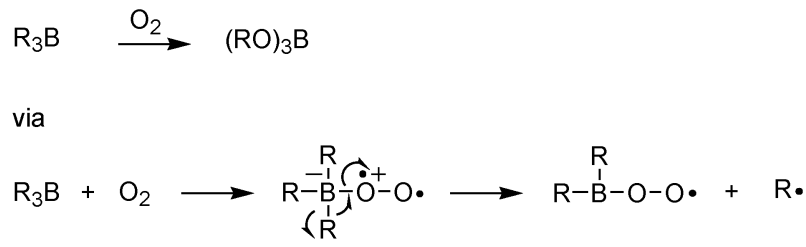

Scheme 1 Autoxidation of organoboranes.

\footnotetext{
*Paper based on a presentation at the $16^{\text {th }}$ International Conference on Organic Synthesis (ICOS-16), 11-15 June 2006, Mérida, Yucatán, México. Other presentations are published in this issue, pp. 153-291.

¥Corresponding author
} 
Interestingly, homolytic substitution at boron does not proceed with carbon-centered radicals. However, many different types of heteroatom-centered radicals (e.g., alkoxyl radicals) react efficiently with the organoboranes (Scheme 2). This difference in reactivity is caused by the Lewis base character of the heteroatom-centered radicals. Indeed, the first step of the homolytic substitution is the formation of a Lewis acid-base complex between the borane and the radical. This complex can then undergo a $\beta$-fragmentation leading to the alkyl radical. This process is of particular interest for the development of radical chain reactions [8].

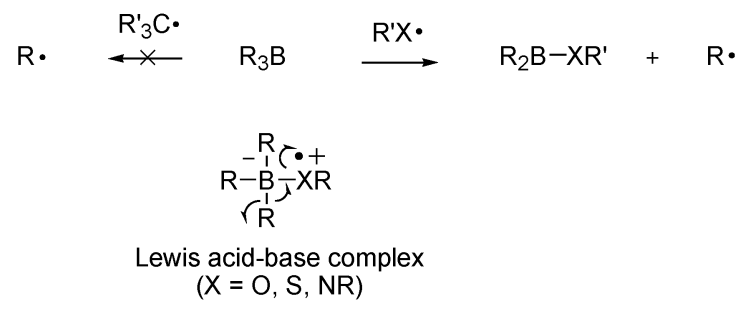

Scheme 2 Reactivity of carbon- and heteroatom-centered radicals toward organoboranes.

In this short overview, we describe some recent results concerning the use of organoboron compounds as well as other boron reagents in radical processes. Examples where the boron derivatives act as a chain-transfer agent, a radical precursor, and a reducing agent will be presented.

\section{TRIETHYLBORANE AS A CHAIN-TRANSFER REAGENT}

The use of triethylborane and other organoboranes as chain-transfer reagents has been recently reviewed [8]. In these processes, the organoborane acts as an initiatior and as a reagent that propagates the chain. Therefore, it has to be used in stoichiometric amount. Recently, we have developed a radical carboazidation [9-12] reaction that has found numerous applications for alkaloid synthesis [13-15]. The chain process requires the transformation of an arylsulfonyl radical into an alkyl radical. Hexabutyldistannane gives excellent results by reacting with the intermediate sulfonyl radical to afford a stannyl radical that can abstract an halogen atom from an alkyl halide [10]. Recently, we have shown that the radical carboazidation of alkenes can be achieved with triethylborane in water according to the mechanism depicted in Scheme 3 [16,17]. This efficient process is completed in one hour at room temperature in an open-to-air reaction vessel. This new tin-free carboazidation procedure is environmentally friendly and allows us to run reactions with an excess of either the alkene or the radical precursor. A typical example of a carboazidation reaction is depicted in Scheme 4 (eq. 1). Direct azidation of radicals generated from alkyl iodides as well as for more complex cascade reactions involving, for instance, annulation are possible (Scheme 4, eq. 2). An excess of triethylborane (3 equiv) and oxygen (open-toair vessel) are required to obtain good yields. This may be an indication that the chain process, more precisely the reaction between the phenylsulfonyl radical and $\mathrm{Et}_{3} \mathrm{~B}$ (Scheme 4, eq. 4), is not efficient and is compensated by the easy generation of ethyl radicals from triethylborane in the presence of air (Scheme 4, initiation step). 


$$
\begin{aligned}
\mathrm{R}^{1}-\mathrm{I}+\mathrm{CH}_{2}=\mathrm{CHR}^{2}+\mathrm{ArSO}_{2}-\mathrm{N}_{3}+\mathrm{Et}_{3} \mathrm{~B} & \longrightarrow \mathrm{R}^{1}-\mathrm{CH}_{2}-\mathrm{CHR}^{2} \mathrm{~N}_{3}+\mathrm{Et}-\mathrm{I}+\mathrm{ArSO}_{2}-\mathrm{BEt}_{2} \\
\mathrm{Et}_{3} \mathrm{~B}+\mathrm{O}_{2} & \longrightarrow \mathrm{Et}_{2} \mathrm{BOO} \cdot+\mathrm{Et} \cdot \quad \text { (initiation) } \\
\mathrm{Et} \cdot+\mathrm{R}^{1}-\mathrm{I} & \longrightarrow \mathrm{Et}-\mathrm{I}+\mathrm{R}^{1} \cdot \\
\mathrm{R}^{1} \cdot+\mathrm{CH}_{2}=\mathrm{CHR}^{2} & \longrightarrow \mathrm{R}^{1}-\mathrm{CH}_{2}-\mathrm{C}(\cdot) \mathrm{HR}^{2} \\
\mathrm{R}^{1}-\mathrm{CH}_{2}-\mathrm{C}(\cdot) \mathrm{HR}^{2}+\mathrm{ArSO}_{2}-\mathrm{N}_{3} & \longrightarrow \mathrm{R}^{1}-\mathrm{CH}_{2}-\mathrm{CHR}^{2} \mathrm{~N}_{3}+\mathrm{ArSO}_{2} \cdot \text { (3) } \\
\mathrm{ArSO}_{2} \cdot \mathrm{Et}_{3} \mathrm{~B} & \longrightarrow \mathrm{Et} \cdot \mathrm{ArSO}_{2}-\mathrm{BEt}_{2}
\end{aligned}
$$

Scheme 3 Mechanism of the $\mathrm{Et}_{3} \mathrm{~B}$-mediated carboazidation.
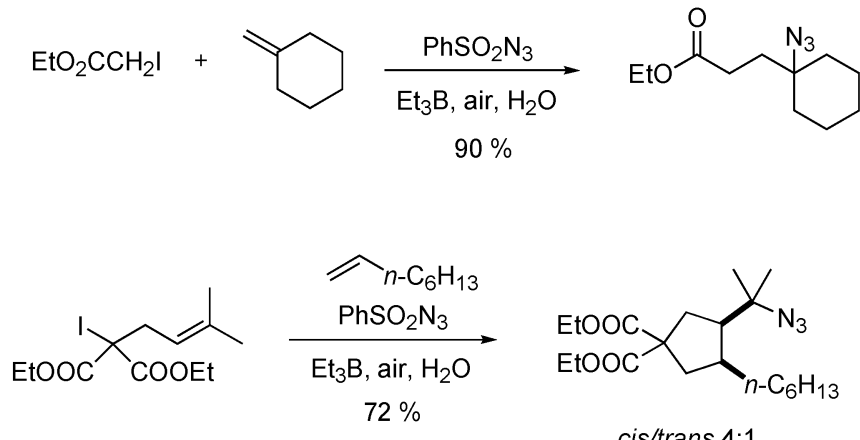

Scheme 4 Triethylborane-mediated carboazidation

\section{B-ALKYLCATECHOLBORANES AS RADICAL PRECURSORS}

\section{Reactivity of $B$-alkylcatecholboranes}

Reactivity of organoboranes toward homolytic substitution by oxygen-centered radicals is dependent on the Lewis acidity of the borane. Davies and Roberts have reported the following reactivity order: $\mathrm{R}_{3} \mathrm{~B}>\mathrm{R}_{2} \mathrm{BOR}>\mathrm{RB}(\mathrm{OR})_{2}$ with $\mathrm{R}=$ alkyl $[18,19]$. Due to $\pi$ bonding between boron and oxygen, boronic esters are less reactive than trialkylboranes toward alkoxyl radicals. Very interestingly, $B$-alkylcatecholboranes (= 2-alkylbenzo[d][1,3,2]dioxaboroles) behave differently. They are extremely sensitive toward oxygen and react readily with alkoxyl radicals. It was demonstrated by electron spin resonance (ESR) that the perboryl radical intermediate resulting from the complexation of $B$-methylcatecholborane with the alkoxyl radical is stabilized by delocalization onto the aromatic ring (Scheme 5) [19].

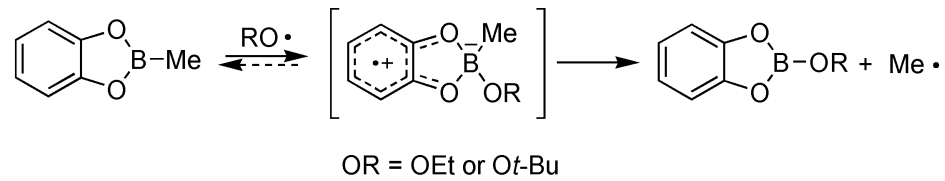

Scheme 5 Reaction of $B$-methylcatecholborane with alkoxyl radicals [19]. 
$B$-Alkylcatecholboranes, easily prepared from olefins via hydroboration with catecholborane, offer the possibility to generate selectively primary, secondary, and tertiary alkyl radicals from a suitable alkene [20]. Indeed, reaction of the $B$-alkylcatecholborane with a heteroatom-centered radical leads in an irreversible manner to the alkyl radical. Possible cleavage of the boron-oxygen bond is a reversible process that finally leads to the irreversible formation of the alkyl radical (Scheme 6).

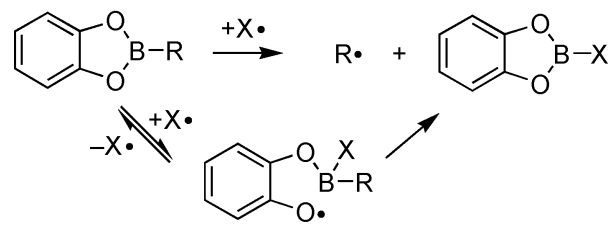

Scheme 6 Irreversible formation of alkyl radicals from $B$-alkylcatecholboranes ( $\mathrm{R}=$ alkyl group).

\section{Conjugate addition}

The radicals generated from $B$-alkylcatecholboranes have been used for conjugate addition to a wide range of $\alpha, \beta$-unsaturated aldehydes and ketones [21,22]. Some typical results are depicted in Scheme 7. The radical derived from an unprotected $\omega$-unsaturated alcohol adds to ethyl vinyl ketone to afford the product of conjugate addition in excellent yield (Scheme 7, eq. 1). This hydroxyketone is a key building block for the synthesis of (-)-dihydropertusaric acid [23]. $\beta$-Substituted enones, such as cyclohexenones, react cleanly with $B$-alkylcatecholborane in the presence of air (Scheme 7, eq. 2) [21]. A cyclization reaction involving a hindered enone is also reported (Scheme 7, eq. 3).

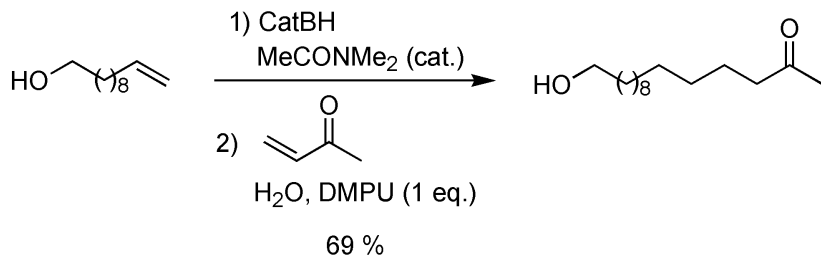<smiles>C1=CCCCC1</smiles>

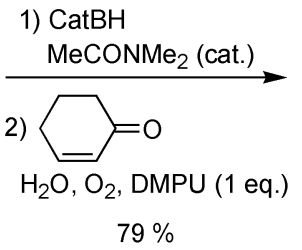<smiles>O=C1CCCC(C2CCCCC2)C1</smiles><smiles>C=CCC1(C)C=C(C)C(=O)C(C)=C1</smiles><smiles>COC(C)(C)CO[N+](=O)OO</smiles><smiles>CC1=C[C@H](C)[C@H](C)CCC1</smiles>

Scheme 7 Conjugate addition to enones.

The mechanism of these conjugate additions is depicted in Scheme 8. It involves the formation of a boron enolate that is hydrolyzed by water under our reaction conditions. The success of this process is related to the high enoxyl character of the intermediate enolate radical adduct. Other classical Michael acceptors such as unsaturated ester, amides, and sulfones do not undergo conjugate addition 


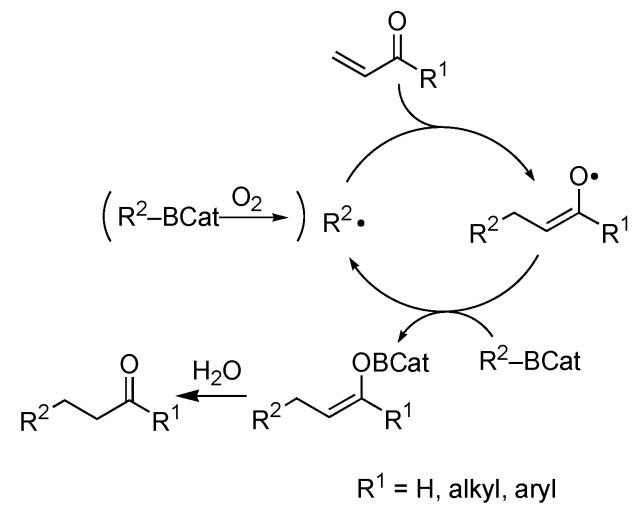

Scheme 8 Mechanism of the conjugate addition to enones and enals.

under these conditions. The use of a chain-transfer reagent allowing one to transform the radical adduct into $O$-centered radicals is necessary to overcome their lack of reactivity $[24,25]$.

\section{Arysulfonyl radical-mediated processes}

The reaction of arenesulfonyl radicals with $B$-alkylcatecholboranes represents a very efficient method for the generation of primary, secondary, and tertiary alkyl radicals (Scheme 8). This process is the key element of several transformations involving $\mathrm{C}-\mathrm{X}$ and $\mathrm{C}-\mathrm{C}$ bond formation.

\section{Allylation}

Radical allylation of $B$-alkylcatecholboranes using easily available allylsulfones has been reported [22,26-28]. By employing allylic phenylsulfones, the fragmentation produces a stable phenylsulfonyl radical that reacts with $B$-alkylcatecholboranes to sustain the chain reaction (Scheme 9). Since oxygencentered radicals react efficiently with $B$-alkylcatecholboranes, the easily available di-tert-butylhyponitrite was selected as an initiator due to its ability to furnish the tert-butoxyl radical at the refluxing temperature of dichloromethane. The thermal properties of this initiator allows us to run a one-pot hydroboration-radical reaction sequence by taking advantage of the very mild, efficient, and cost-effective hydroboration conditions developed by Fu [29].

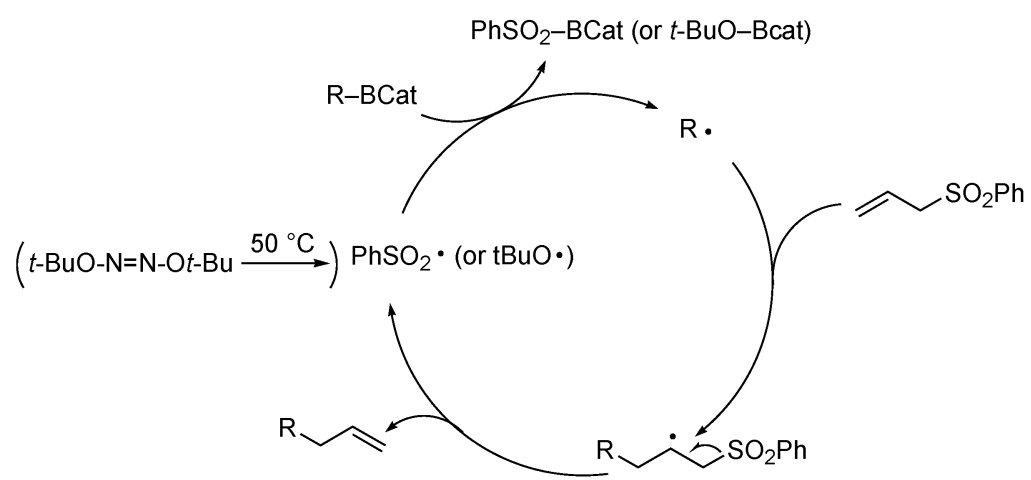

Scheme 9 Mechanism of the allylation of $B$-alkylcatecholboranes. 
The desired products were obtained in satisfactory to excellent yields by using only 1.2 equiv of the allylsulfones with primary, secondary, and tertiary alkyl radicals [22,26,28]. Many different types of allylic sulfones bearing an ester group, a sulfonyl group, and a bromine atom react equally well (Scheme 10). The whole transformation represents formally a reductive allylation or hydroallylation of alkenes.

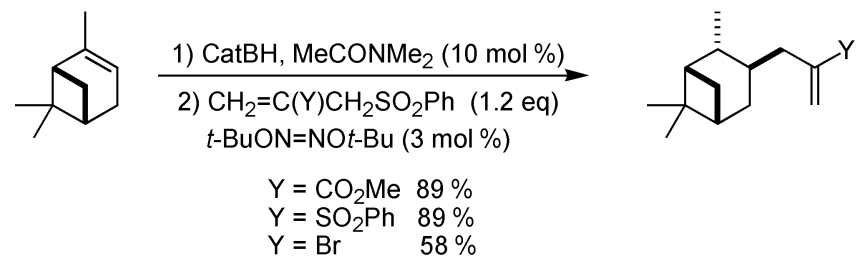

Scheme 10 Allylation of $B$-alkylcatecholboranes with allylsulfones.

Interestingly, this allylation process seems to be very general. For instance, introduction of a dienyl moiety using penta-2,4-dienyl phenyl sulfone has been achieved (Scheme 11, eq. 1). The modest yield $(50 \%)$ for the conversion is due to the instability of the dienyl sulfone, which readily polymerizes. Finally, the radical nature of the process has been demonstrated by running an allylation reaction with (+)-2-carene (Scheme 11, eq. 2). With this radical probe, the intermediate cyclopropylmethyl radical undergoes ring-opening to a homoallylic radical that is trapped by the allylic sulfone to afford the corresponding monocyclic compound in $58 \%$ yield.
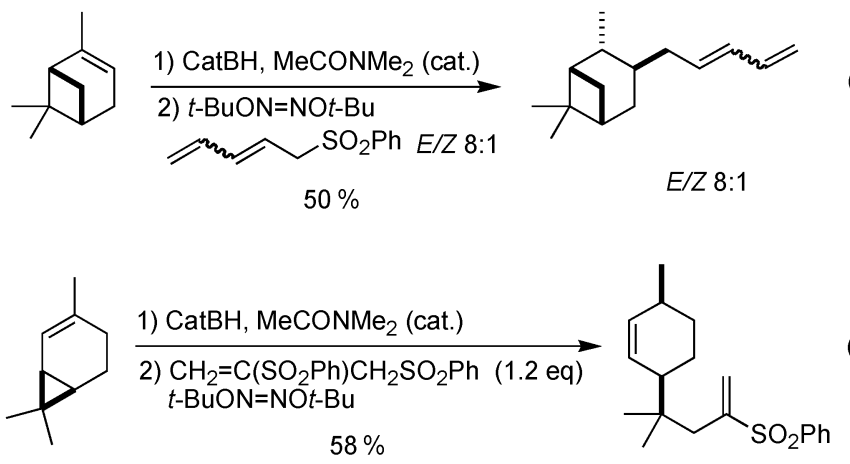

Scheme 11 Introduction of a dienyl moiety using penta-2,4-dienyl phenyl sulfone (eq. 1) and hydroallylation of (+)-2-carene (eq. 2).

Radical coupling of $B$-alkylcatecholboranes, generated in situ from the corresponding alkenes with ethyl 2-(benzenesulfonylamino)acrylate is reported (Scheme 12) [27]. This reaction represents an extension of the radical allylation of $B$-alkylcatecholboranes by allylsulfones. This unique process allows us to prepare various $\alpha$-ketoesters (alkylated pyruvates) in a straightforward manner. It also demonstrates the generality of the radical-mediated $\mathrm{C}-\mathrm{C}$ bond formation starting from organoboranes and allylic benzenesulfonyl derivatives. 


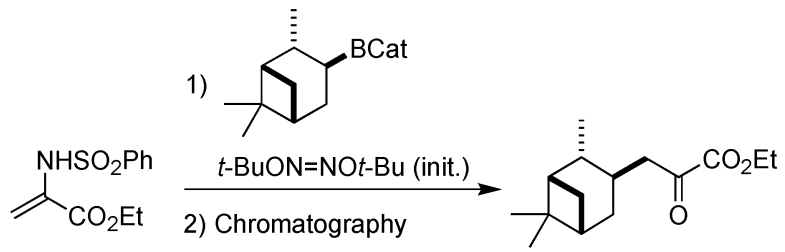

Scheme 12 Alkylation of ethyl pyruvate via reductive coupling of alkenes and ethyl 2-(benzenesulfonylamino)acrylate.

A tandem radical process involving conjugate addition to an activated alkene followed by allylation has been developed (Scheme 13) [30]. The reaction is efficient with electrophilic alkenes such as phenyl vinyl sulfone, $N$-phenylmaleimide, and dialkyl fumarate. The whole process can be considered as a unique and selective coupling of three different alkenes.

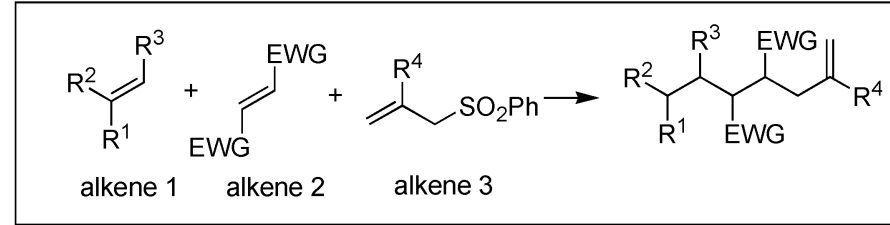

$E W G=$ electron withdrawing group

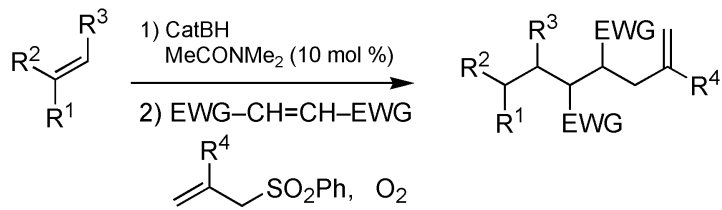<smiles>[R]C(=C)CC(CC1CCCCC1)S(=O)(=O)Oc1ccccc1</smiles>

$\mathrm{R}^{4}=\mathrm{H}(68 \%)$

$\mathrm{R}^{4}=\mathrm{Me}(70 \%)$

$\mathrm{R}^{4}=\mathrm{CH}_{2} \mathrm{Cl}(82 \%)$<smiles>[R]CCCC(CC([R])=C)S(=O)(=O)Oc1ccccc1</smiles>

$\mathrm{R}^{1}=n-\mathrm{C}_{6} \mathrm{H}_{13}, \mathrm{R}^{4}=\mathrm{H}(71 \%)$

$\mathrm{R}^{1}=n-\mathrm{C}_{6} \mathrm{H}_{13}, \mathrm{R}^{4}=\mathrm{Me}(61 \%)$

$\mathrm{R}^{1}=\mathrm{R}^{4}=\mathrm{Me}(61 \%)$

$\mathrm{R}^{1}=\mathrm{Me}, \mathrm{R}^{4}=\mathrm{CH}_{2} \mathrm{Cl}(63 \%)$

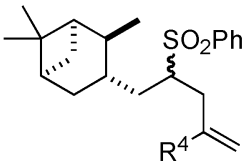

$\mathrm{R}^{4}=\mathrm{H}(76 \%, \mathrm{dr} 3: 1)$

$\mathrm{R}^{4}=\mathrm{Me}(76 \%$, dr 3:1)

$\mathrm{R}^{4}=\mathrm{CH}_{2} \mathrm{Cl}(79 \%, \mathrm{dr} 3: 1)$

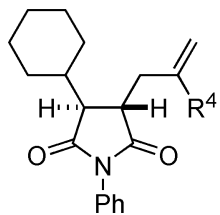

(trans/cis $\geq 95: 5$ )

$\mathrm{R}^{4}=\mathrm{H}(56 \%)$

$\mathrm{R}^{4}=\mathrm{Me}(57 \%)$

$\mathrm{R}^{4}=\mathrm{CH}_{2} \mathrm{Cl}(59 \%)$<smiles>C=C(C)C[C@H](CCC1CC[C@@H]2CC1C2(C)C)S(=O)(=O)c1ccccc1</smiles>

$(71 \%$, dr $1: 1)$<smiles>[R]C(=C)C[C@@H](C(C)=O)C(COC)C1CCCCC1</smiles>

(anti/syn $\geq 92: 8$ )

$\mathrm{R}^{4}=\mathrm{H}(61 \%)$

$\mathrm{R}^{4}=\mathrm{Me}(72 \%)$

$\mathrm{R}^{4}=\mathrm{CH}_{2} \mathrm{Cl}(68 \%)$

Scheme 13 Three-component coupling of alkenes involving a tandem radical conjugate addition-allylation process. 


\section{Alkenylation and methanimination [31]}

The $\beta$-fragmentation of arenesulfonyl radicals can also be used to make $\mathrm{C}-\mathrm{C}$ bonds between $\mathrm{sp}^{3}$ and $\mathrm{sp}^{2}$ centers. These reactions are based on a common process, i.e., radical addition to the carbon atom of a double bond bearing an arenesulfonyl group followed by a $\beta$-fragmentation (Scheme 14).

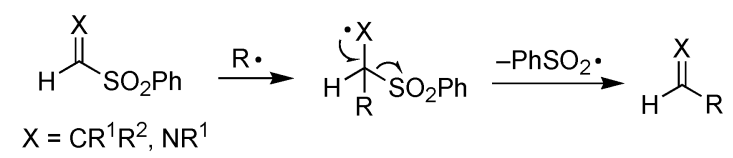

Scheme 14 Mechanism of the alkenylation and methanimination.

In situ treatment of the $B$-alkylcatecholborane with 2-phenylethenyl and 2-phenylsulfonylethenyl sulfones (1.2-3 equiv) in the presence of di-tert-butyl hyponitrite (initiator, $3 \mathrm{~mol} \%$ ) affords the expected alkenylated products in fair yields (Scheme 15). The bissulfone is a very convenient reagent for the vinylation reaction, and no product resulting from the bis-substitution of the two sulfonyl group is detected (Scheme 15, eq. 1). It affords alkenylsulfones as products that are interesting starting material for further functionalization. The use of phenyl 2-phenylvinyl sulfone allows the introduction of a styryl group (Scheme 15, eq. 2).

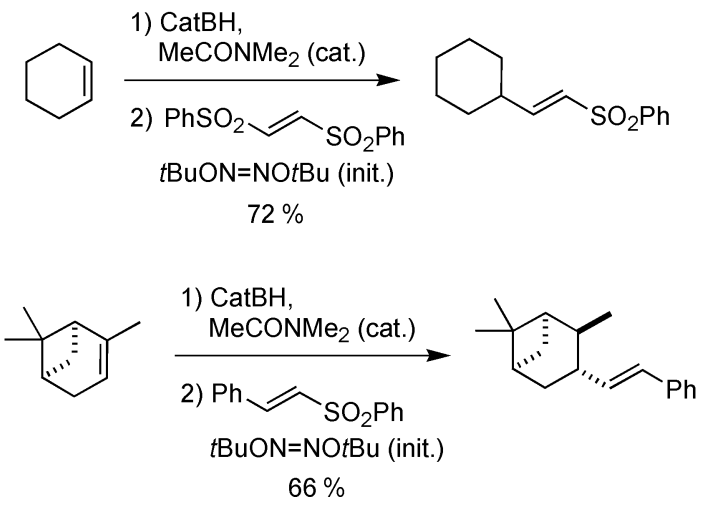

Scheme 15 Radical alkenylation of $B$-alkylcatecholboranes.

An acylation protocol was then tested using Kim's $N$-benzyloxy-1-(phenylsulfonyl)methanimine (Scheme 16) [32]. Primary and secondary alkyl radicals react well and afford the stable oxime ethers. This transformation corresponds formally to a formylation of the $B$-alkylcatecholborane.

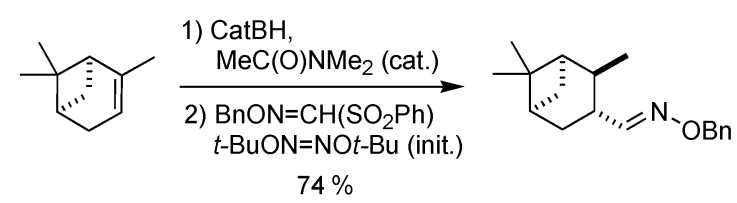

Scheme 16 Methanimination reaction of $B$-alkylcatecholboranes. 
Alkynylation and cyanation [31]

Reaction with alkynyl sulfones allows us to perform an alkynylation process according to Scheme 17.

$$
\begin{aligned}
& \mathrm{PhO}_{2} \mathrm{~S}-\mathrm{C} \equiv \mathrm{X} \stackrel{\mathrm{R} \cdot}{\longrightarrow} \mathrm{R} \stackrel{\mathrm{H}^{\cdot} \mathrm{H}_{\mathrm{SO}}}{\mathrm{SO}_{2} \mathrm{Ph}} \stackrel{-\mathrm{PhSO}_{2} \cdot}{\longrightarrow} \mathrm{R}-\mathrm{C} \equiv \mathrm{X} \\
& \mathrm{X}=\mathrm{CR}^{1}, \mathrm{~N}
\end{aligned}
$$

Scheme 17 Mechanism for the radical alkynylation and cyanation.

This reaction is particularly interesting since this type of cross-coupling between alkylboranes and acetylene derivatives is not well documented. The reaction with phenyl phenylethynyl sulfone is efficient with primary to tertiary alkyl radicals (Scheme 18, eq. 1). Interestingly, similar results were obtained with the trimethylsilylethynyl phenyl sulfone (Scheme 18, eq. 2). This result is best explained by the steric hindrance of the $\mathrm{Me}_{3} \mathrm{Si}$ group that favors addition at the $\alpha$ position of the sulfonyl group.

Finally, a related cyanation process was attempted using commercially available $p$-toluenesulfonyl cyanide according to Scheme 19 . Good yields are obtained with primary and secondary radical (Scheme 19, eq. 1). Reaction with (+)-carene affords monocyclic cyanide resulting from the isomerization of the cyclopropylmethyl radical to a homoallyl radical (Scheme 19, eq. 2). The cyanation of organoboranes has also, to the best of our knowledge, no precedent in the literature.
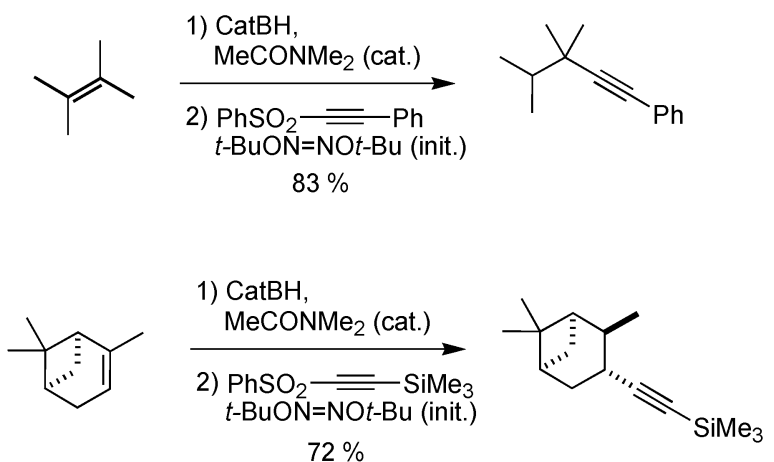

Scheme 18 Radical alkynylation of $B$-alkylcatecholboranes.

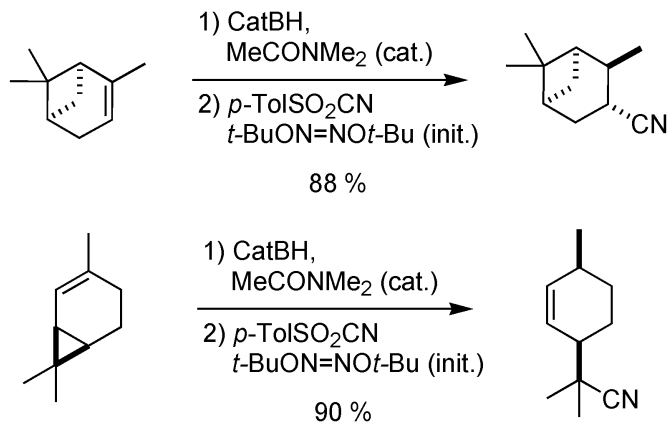

Scheme 19 Radical cyanation of organoboranes. 


\section{BORON-ALCOHOL COMPLEXES AS REDUCING AGENTS}

A mild and efficient radical-mediated reduction of organoboranes has been developed (Scheme 20) [33]. An in situ-generated $B$-methoxycatecholborane-methanol complex acts as a reducing agent. The radical nature of the process was demonstrated by using (+)-2-carene as a radical probe (Scheme 20, eq. 2). Water and ethanol can be used instead of methanol with very similar efficiency [34].
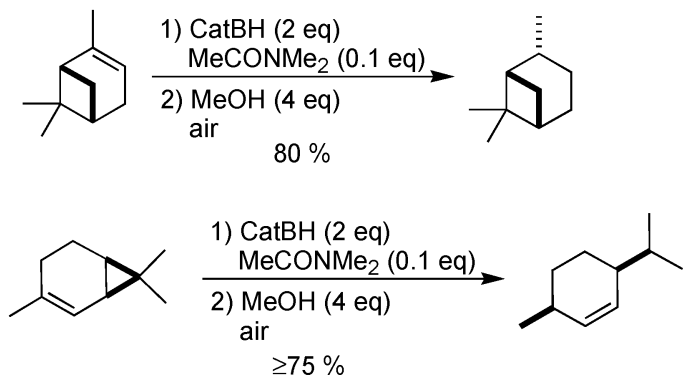

Scheme 20 Mild radical-mediated reduction of organoborane with methanol.

The reaction mechanism of this transformation is depicted in Scheme 21 and involves activation of the $\mathrm{O}-\mathrm{H}$ bond of methanol by complexation with $B$-methoxycatecholborane. Interestingly, the reduction leads after fragmentation of the radical-ate complex to a methoxyl radical that reacts very efficiently with the $B$-alkylcatecholborane, warranting an efficient chain process.

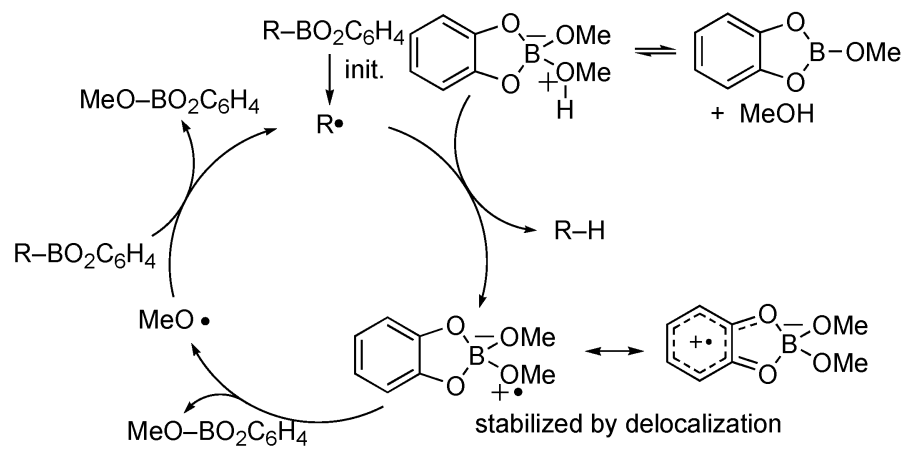

Scheme 21 Chain mechanism of the reduction of organoboranes.

\section{CONCLUSIONS}

The tremendous development of the use of radicals in organic synthesis and the necessity to avoid the use of tin derivatives because of their toxicity have led to a revival of the radical chemistry of organoboranes. The use of triethylborane as an initiator for radical chain reactions is now part of the classical tools of organic chemists. Generation of more complex and functionalized radicals from organoboranes is of great interest since it allows one to consider olefins as potential source of radicals. So far, the generation of radicals has not been extended to alkenyl and aryl radicals, but rapid progress is expected in this field. Interestingly, organoboranes could also play the role of chain-transfer reagents in radical processes. Due to the particularly rich reactivity of boron derivatives, the design of tandem processes involving radical and non-radical reactions is now possible. Finally, boron derivatives are promising 
reagents to activate water and alcohols and to make them suitable reagents for the reduction of radicals. Spectacular development in this particular field is expected in a near future.

\section{ACKNOWLEDGMENTS}

We are very grateful to the Swiss National Science Foundation for financial support. We thank BASF Corporation for the generous gift of organoboron reagents.

\section{REFERENCES}

1. H. C. Brown, M. M. Midland. Angew. Chem., Int. Ed. Engl. 11, 692 (1972).

2. A. Ghosez, B. Giese, H. Zipse. Houben-Weyl, Vol. E19a, p. 753 (1989).

3. C. Ollivier, P. Renaud. Chem. Rev. 101, 3415 (2001).

4. A. G. Davies, B. P. Roberts. Acc. Chem. Res. 5, 387 (1972).

5. A. G. Davies. Pure Appl. Chem. 39, 497 (1974).

6. K. Nozaki, K. Oshima, K. Utimoto. J. Am. Chem. Soc. 109, 2547 (1987).

7. H. Yorimitsu, K. Oshima. In Radicals in Organic Synthesis, Vol. 1, P. Renaud, M. P. Sibi (Eds.) p. 11, Wiley-VCH, Weinheim (2001).

8. V. Darmency, P. Renaud. In Topics in Current Chemistry, Vol. 263, A. Gansaeuer (Ed.), p. 71, Springer, Berlin (2006).

9. C. Ollivier, P. Renaud. J. Am. Chem. Soc. 122, 6496 (2000).

10. C. Ollivier, P. Renaud. J. Am. Chem. Soc. 123, 4717 (2001).

11. P. Renaud, C. Ollivier, P. Panchaud. Angew. Chem., Int. Ed. 41, 3460 (2002).

12. P. Panchaud, L. Chabaud, Y. Landais, C. Ollivier, P. Renaud, S. Zigmantas. Chem. Eur. J. 10, 3606 (2004).

13. P. Panchaud, C. Ollivier, P. Renaud, S. Zigmantas. J. Org. Chem. 69, 2755 (2004).

14. L. Chabaud, Y. Landais, P. Renaud. Org. Lett. 7,2587 (2005).

15. P. Schär, P. Renaud. Org. Lett. 8, 1569 (2006).

16. P. Panchaud, P. Renaud. J. Org. Chem. 69, 3205 (2004).

17. P. Panchaud, P. Renaud. Adv. Synth. Catal. 346, 925 (2004).

18. A. G. Davies, B. P. Roberts. Free Radicals, Vol. 1, J. K. Kochi (Ed.), p. 457, John Wiley, New York (1973).

19. J. A. Baban, N. J. Goodchild, B. P. Roberts. J. Chem. Soc., Perkin Trans. 2157 (1986).

20. A.-P. Schaffner, P. Renaud. Eur. J. Org. Chem. 2291 (2004).

21. C. Ollivier, P. Renaud. Chem. Eur. J. 5, 1468 (1999).

22. A.-P. Schaffner, B. Becattini, C. Ollivier, V. Weber, P. Renaud. Synthesis 2740 (2003).

23. A. Brecht-Forster, J. Fitremann, P. Renaud. Helv. Chim. Acta 85, 3965 (2002).

24. C. Ollivier, P. Renaud. Angew. Chem., Int. Ed. 39, 925 (2000).

25. B. Becattini, C. Ollivier, P. Renaud. Synlett 1485 (2003).

26. A.-P. Schaffner, P. Renaud. Angew. Chem., Int. Ed. 42, 2658 (2003).

27. V. Darmency, P. Renaud. Chimia 59, 109 (2005).

28. V. Darmency, E. M. Scanlan, A. P. Schaffner, P. Renaud. Org. Synth. 83, 24 (2005).

29. C. E. Garett, G. C. Fu. J. Org. Chem. 61, 3224 (1996).

30. A. P. Schaffner, K. Sarkunam, P. Renaud. Helv. Chim. Acta 89, 2450 (2006).

31. A. P. Schaffner, V. Darmency, P. Renaud. Angew. Chem., Int. Ed. 45, 5847 (2006).

32. S. Kim, I. Y. Lee, J.-Y. Yoon, D. H. Oh. J. Am. Chem. Soc. 118, 5138 (1996).

33. D. Pozzi, E. M. Scanlan, P. Renaud. J. Am. Chem. Soc. 127, 14204 (2005).

34. D. A. Spiegel, K. B. Wiberg, L. N. Schacherer, M. R. Medeiros, J. L. Wood. J. Am. Chem. Soc. 127, 12513 (2005). 